Send your letters to the editor, British Dental Journal, 64 Wimpole Street, London W1G 8YS E-mailbdj@bda.org

Priority will be given to letters less than 500

words long. Authors must sign the letter,

which may be edited for reasons of space-

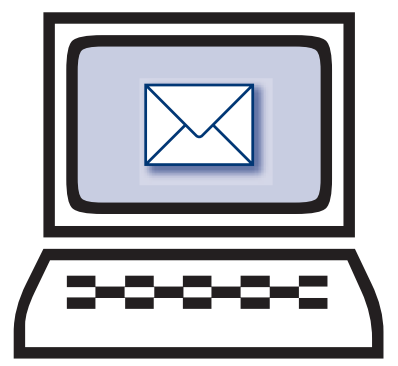

biased in favour of the PAD, and it is my assumption that this may have accounted for the observed fall in microbes following PAD treatment. If sodium hypochlorite was reintroduced having enlarged the canal a similar effect may have resulted.

Therefore, it is difficult to conclude from this study that PAD is more effective than sodium hypochlorite as a disinfectant, even though the authors' discussion implied that it was. If the authors' results were obtained without altering the canal dimensions during sampling then indeed PAD could be shown (taking into account the small sample size) to be a useful adjunct to sodium hypochlorite but this was clearly not the case.

\section{G. Karunanayake}

By email

doi: $10.1038 /$ sj.bdj.4813726

\section{Unproven case}

Sir, in support of Dr Qualtrough's comment (BDJ 2006; 200: 329) to treat the study by Bonsor et al. (BDJ 2006; 200: 337-341) with caution, I would like to share the following observations.

1. The study was stated as a randomised trial but the only randomisation procedure was in the recruitment of patients, whether a patient was selected or not. The sample size was small; there were no proper controls and no statistical analysis.

2. Microbial sampling and culturing from the root canal are exacting procedures and were developed based mainly on Moller's ${ }^{1}$ classical thesis. The canal sampling method used in this study has little in common with recognised protocol.

3. Rubber dam was only placed after access to the pulp chamber was gained despite the awareness of the risk of contamination.

4. O'Neil et al. (2002) were quoted in support of effective disinfection of the operating field after rubber dam placement. However, no field samples were taken for confirmation.

5. A chosen canal, not each canal, in a multi-rooted tooth should be a test unit.
6. For maximum efficacy, the emitter was placed within $4 \mathrm{~mm}$ of the canal length. Since no radiographic determination of canal length was performed, the emitter may be within $4 \mathrm{~mm}$ of the estimated but not necessarily the true canal length.

7. An irrigant should never be 'injected' because of the risk of extrusion.

8. Only sterile water but no inactivating solution eg sodium thiosulphate was used prior to taking Sample B.

9. The three cases pretreated with Ledermix should have been excluded.

10. It is common practice to leave sodium hypochlorite to soak in root canals to improve disinfection. Unlike the photosensitiser, sodium hypochlorite was not given diffusion time.

11. The statement (line 15) in Results about confirmation that crosscontamination did not occur is unconvincing.

12. The toxicity of sodium hypochlorite is increased at higher concentrations but toxicity is also related to $\mathrm{pH}$. Therefore, a higher concentration does not necessarily mean greater toxicity.

13. In Discussion, the claim that the results of the study demonstrated the reliability of their technique is questionable.

14. The emitter is equivalent to ISO \#40 so canals have to be prepared accordingly. Apart from the risks and difficulties in preparing to this size eg mesial roots of mandibular molars, by the time this was attained, significant disinfection was achieved (80\%). PAD led to further improvement (15\%) but not total bacterial eradication so an intracanal medicament is still required.

15. The first line in Conclusions should be qualified - 'The results of this limited study show....

16. The last two In Brief bullet points should also be qualified -

- Conventional chemo-mechanical canal preparation techniques may not always disinfect the canals predictably and consistently.

- PAD may offer, as an adjunct, the potential to eliminate bacteria from 
the root canals especially where conventional techniques may have failed to do so.

PAD may have the potential to improve root canal disinfection but from this study, the case is far from proven.

\section{B. S. Chong}

London

1. Möller Å J R. Microbiological examination of root canals and periapical tissues of human teeth. Methodological studies. Göteborg: Akademiförlaget, 1966.

The authors, S. Bonsor and G. Pearson, respond to the above three letters: We would like to thank Drs Chong, Karunanayake and Watson for their interest and comments on the article on $P A D$.

May we correct some errors of fact in the letters?

1. The canals were prepared Profile 0.4 rather than 0.6 as suggested in one letter.

2. The teeth where Ledermix was used were excluded from the results in Figure 3 and this is stated in the text.

3. The photosensitiser is not an irrigant as indicated by respondents. It is a solution which when activated by light provides singlet oxygen which kills the bacteria. As such the volume used is that required to fill the lumen of the canal. This volume is delivered by the use of a safe ended endodontic needle passively inserted into the lumen of the canal to prevent extrusion of fluid beyond the apical foramen. This is followed by gentle agitation with a hand instrument to eliminate air bubbles. No 'active irrigation' of the photosensitiser was carried out.

4. The use of prolonged saturation of hypochlorite in the canal was demonstrated in that the canal preparations were carried out over periods of between 20 and 30 minutes evidenced by the recorded time at which samples were taken. During that time there was copious irrigation with the co-irrigants: hypochlorite and citric acid.

5. The emitter tip is of a size such that it will reach to within $3 \mathrm{~mm}$ of a canal which has been prepared with a size 25 instrument of the conventional 02 ISO standard and would not therefore have been over-prepared as suggested. Laboratory studies have shown that light transmission in air is unattenuated and that passage down a canal even with a curvature is not affected as little attenuation occurs even on passage through $3 \mathrm{~mm}$ of dentine.
With regards to the other points raised, the following should also be borne in mind:

\section{Randomisation}

In the context of this trial the patients were a random sample of those requiring endodontic therapy. No prior screening was carried out to select patients for inclusion.

\section{Controls}

This study was an initial investigation of a technique which had been evaluated in considerable depth in the laboratory. ${ }^{1}$ Within this study an attempt was made to examine the effect of using the technique as an adjunct to the current therapy which, while being good, is not foolproof. The option would exist to have a sample group where the canal was left open for the period of time equivalent to the time that the photosensitiser would be in the canal ie three minutes and then sample again. This was considered and a number of preliminary samples were taken of teeth at these specific points in an endodontic procedure to explore the differences. No difference in bacterial load was found and it was therefore decided that the initial sample was a representative example of the canal as prepared by the operator at a point where it would normally be filled.

\section{Blinding}

In respect to the blinding of the trial the treatment regiment was identical in all cases and the blinding was achieved by the fact that the microbiological samples (the only aspect where bias is likely to have occurred) was carried out by a member of the Microbiological Department of the hospital with no knowledge of the coding system which was used in the clinic.

\section{Numbers}

Numbers of cases in studies are always a problem and we would be the first to acknowledge that the numbers in this study are limited. This was pointed out by the commentator Dr Qualtrough on page 329 of the journal. However, microbiological studies are regularly carried out worldwide in the endodontic arena and the numbers quoted here are similar to a large number of other studies. In fact, a substantial number of comparative studies of effectiveness of materials / medicaments in endodontics use a similar range of numbers in each test. Pinherio et al. $2004(n=21)$, Attin et al. 2002 ( $n=22$ ), Kont Cobankara et al. 2002 ( $n=10$ in each group) are some of the examples of this. ${ }^{2-4}$

Rubber dam placement

This was placed after access to the pulp chamber as it is a well known complication that loss of tooth angulation when dam is in situ can cause iatrogenic damage during pulp chamber access. The dam was placed before any canal cleaning and so if contamination had occurred then sample A would have shown a higher result, potentially allowing a greater fall off of bacterial numbers at sample B thus if anything, showing a greater effect of conventional techniques.

\section{Estimation of canal length}

An apex locator was used to determine the working length of the canal and then this was confirmed radiographically at the cone fit stage. This is a recognised technique for determining the working length. It is well documented that apex locators provide a precise estimate of canal length and indeed have been shown to be more accurate than the use of a diagnostic file radiograph. 5,6

\section{Irrigation of the canal}

It should also be borne in mind that in the intervening time between the sampling after hypochlorite irrigation and sampling for $P A D$, the canal was only filled with photosensitiser solution and agitated with a hand instrument. No irrigation in the normal endodontic meaning of the word was carried out. Hence the flow volume and change to canal wall would not affect the results as Dr Karunanayake implies. This point also relates to one of those raised by $\mathrm{Dr}$ Watson as the canal was not actively irrigated with PAD solution just filled unlike the use of hypochlorite where continuous flushing out is advised.

Neutralisation of the sodium hypochlorite This is an interesting point particularly since the photosensitiser is a light blue colour which is bleached by sodium hypochlorite. In fact the concentration of bleach required to achieve this is a $0.0032 \%$ solution. Since the concentration use in the study was greatly in excess of this (2.25\%), the presence of any residual hypochlorite would therefore have easily been recognised as the photosensitiser would have bleached. This phenomenon was not observed.

A canal opposed to a tooth as a test unit It was shown with the results gained that no cross contamination of multirooted teeth took place. Furthermore it is well known that in multi-rooted teeth, different canals may exhibit different stages of pathology and apical pathology concurrently and hence bacterial loads. Sampling of each canal was therefore fully justified. Interestingly if the tooth 
is treated as the unit the results for the current study are similar with a 15\% increase in canals with no culturable bacteria after PAD application.

\section{Sampling}

The use of an instrument to sample the walls has previously been reported by a number of works including Hancock et al. ${ }^{7}$ The method of sampling here requires that the instrument be drawn up the side of the wall as it is moved circumferentially round the canal such that swarf and debris from the canal wall would be collected. This would pick up material particularly in the apical third.

\section{Change in canal volume}

An interesting point is raised as to the comparative changes within the root canal as a result of the method of sampling and suggests that this would influence the outcome. This was a point of discussion in the preamble to the study and calculations were made as to the effect that the removal of swarffrom the apical part of the canal which is primarily involved would mean in terms of volume involved. The volume change in the apical $4 \mathrm{~mm}$ by increasing instrument size is from 0.00034 cc to $0.00044 \mathrm{cc}$. The variation in solution volume is therefore $0.0001 \mathrm{ml}$. There may therefore be a slight change in canal geometry but certainly not of any significant effect.

\section{Toxicity of sodium hypochlorite}

It is well accepted that the toxicity of sodium hypochlorite is $\mathrm{pH}$ dependent. However at the $\mathrm{pH}$ commonly used in endodontics, particularly in the absence of any buffering, the higher the concentration at the specific $\mathrm{pH}$ the more likely to produce tissue damage as instanced by the references reported in the article.

Intra-canal medicament required Dr Chong mentions the need for intra canal medication after treatment. While this was not directly part of the study, Calcium hydroxide was placed in all canals after sampling and root canal preparation. This would not necessarily have dealt with species such as E or $S$ faecalis even if these organisms were present after treatment since calcium hydroxide is ineffective against these organisms. ${ }^{8,9}$

\section{Statistical analysis}

The objective of the trial was, as stated earlier, a preliminary trial to examine the possible effect of the technique as an adjunct to conventional therapy. To this end, complex statistical analysis would be inappropriate. However, without pre- empting future publications in press, statistical analysis in a larger study directly comparing differing methods of disinfection suggest that photo-activated disinfection is an effective alternative to conventional disinfectants.

1. Williams J A, Colles M J, Pearson G J et al. Antibacterial action of photo-activated disinfection used on endodontic bacteria in planktonic suspension and in artificial and human root canals. $J$ Dent in press. Available online as galley proofs.

2. Pinheiro ET, Gomes B P F A, Drucker D B et al. Antimicrobial susceptibility of $E$ faecalis isolates from canals of root canal filled teeth with periapical lesions. Int Endod J 2004; 37: 756-763.

3. Attin T, Buchalla W, Zirkel C, Lussi A. Clinical evaluation of the cleansing properties of noninstrumental techniques for cleaning root canals. Int Endod J 2002; 35: 929-933.

4. Kont Cobankara F, Adanir N, Belli S, Pashley D H. A quantitative evaluation of apical leakage of four root canal sealers. Int Endod J 2002; 35: 979-984.

5. Gordon M P J, Chandler N P. Electronic apex locators. Int Endod J 2004; 37: 425-437.

6. McDonald N J. The electronic determination of working length. Dental Clinics of North America 1992; 36: 293-307.

7. Hancock H H, Sigurdsson A, Trope M, Moiseiwitch J. Bacteria isolated after unsuccessful endodontic treatment in a North American population. Oral Surg Oral Med Oral Pathol 2001: 91:579-585.

8. Bystrom A, Claesson R, Sundquist G. The antibacterial effect of camphorated paramonochlorophenol, camphorated phenol and calcium hydroxide in the treatments of infected root canals. Endod Dent Traumatol 1: 170-175.

9. Safavi K E, Spangberg LS W, Langeland K. Root canal dentinal tubule infection. J Endod 1990; 16: 207210.

doi: 10.1038/sj.bdj.4813727

\section{Pandemic flu}

Sir, as far as we can ascertain there is a lack of information available to dentists on what to do in the event of pandemic flu. We here in Hillingdon have produced the following information and thought that it may be of interest to $B D J$ readers.

There is much contingency planning taking place in anticipation of pandemic flu. ${ }^{1}$ Although there remain questions over the timing and the severity, most experts say it is not a question of if but when. Extensive advice for the general public is in preparation, which will include restricting unnecessary travel and gatherings. There is likely to be a certain amount of general disruption. The flu virus is expected to spread mostly through droplets and it is feasible that some people will be infectious before they are symptomatic. ${ }^{2}$ At the start of the pandemic, there will be no vaccine for protection. In these circumstances, it may not be wise to try to continue with routine non-urgent dentistry, even assuming patients would want to attend. Like many small businesses, GDPs might expect a few lean months.

Other primary care colleagues meanwhile are expecting to be overwhelmed. There will be a national campaign to encourage self-help and using the phone as much as possible for advice. Even so, both pharmacists and GPs may anticipate a huge added burden, not least because of having to deal with all those with non-flu illnesses unable to access their usual hospital care. PCTs are charged with planning for how to cope with the community burden, and are looking for creative solutions for staffing their response, made all the more difficult by staff illness. ${ }^{3}$

Dental practitioners and their staff have many of the generic skills that will be needed for the clinical flu effort. There are the basics of record-keeping, dealing with the distressed public, confidentiality and infection control. GDPs also have prescribing powers without needing to use the PGD (Patient Group Directives) planned for other groups. When debating this locally some years ago, there was an outline agreement with the LDC that dentists would be encouraged to volunteer to make themselves and their staff available to help out their medical colleagues. This may be to help staff flu treatment centres, or help fill backroom roles in general medical practices.

Suggestions are needed for the best ways of achieving this for those dentists that are willing, recognising the flexibilities in the new dental contract. This may need to be facilitated by the centre and implemented locally, in discussions between the LDC and PCTs. In return for being part of the pandemic flu emergency primary and community care workforce, the system would need to ensure dentists continue with their remuneration, get temporary relief from their targets and have any indemnity issues covered. Ready-made templates for delivering this package already agreed with the profession would help local planning.

We are confident that many dental practice staff will want to show their professionalism and rise to the occasion rather than hibernate for the duration. H. Pickles

R. Rattan

J. Asquith

Hillingdon

1. UK Influenza Pandemic Contingency Plan (October 2005) on www.dh.gov.uk/assetRoot/04/12/17/44/041 21744.pdf

2. HPA Influenza Pandemic Contingency plan (Oct 05) on www.hpa. org.uk/infections/topics_az/influenza/ pdfs/HPAPandemicplan.pdf

3. Hall L, Whitehouse J, Pickles H. Family friendly policies at times of crisis. 2001. Hillingdon Annual Public Health Report pp26-27 on www.hillingdon. nhs.uk under public health

doi: $10.1038 /$ sj.bdj.4813728

\section{Is it me?}

We are a two dentist practice who were in PDS for 20 months before 1 April 2006. 
PDS was working well and we were very happy and surprised that a change to our way of working was beneficial to our quality of working life and our patients.

For existing PDS practices the work reflected in the test period has not been translated to the nPDS UDA target. This is because of increases by PCTs to UDA totals to try and protect themselves against a patient revenue shortfall, for which they will be responsible under the new contract.

Approximate calculations of surgery time for treating NHS patients (taking into account time for CPD, Clinical Governance, Good Practice Scheme, practice meetings, holidays etc) give us each a target of 6.2 UDAs per hour. The acting Chief Dental Officer has suggested that a reasonable rate of work is 3 UDAs per hour.

While it is relatively easy to work at a rate of 6 UDAs per hour, eg two fillings, one filling and three check-ups, it is not easy to be rewarded with 6 UDAs per hour as they are of course only measured on completed treatments. We may have to forget about time for prevention due to pressures of UDAs.

The Government spin to take dentists off the treadmill by only measuring courses of treatment sounds good, but targets are of course dependent on the length of a course of treatment. These vary tremendously - I have a patient to be seen today who requires at least 10 teeth filling, a thorough scaling, and an extraction - not good value for 3 UDAs if you have to provide the treatment.

The CDO would probably argue that the patient whom you see, who requires one filling that can be done at the recall appointment, will generate 3 UDAs in about 15 minutes. This is fair comment, but how do we know that the swings will equate to the roundabouts in this untested UDA system? I don't think that they will, especially in an unfluoridated area of high dental disease. Is it a fair form of remuneration? Again, I think not.

The effect that this will have is an incentive to actively treat whether necessary or not, no incentive to produce quality work and certainly not to welcome new patients or lapsed attendees, who may well require much more work in return for the UDAs that they produce.

While the political spin 'opens up dental surgeries as NHS access centres' by finishing with patient registrations, we all know that this will not increase new patient access as practices are already working to capacity.

There are further problems when an associate or partner leaves. These changes are not taken into consideration by the new contract. The vacancy created has a financial and UDA value. This may exceed the capabilities of the new dentist, or indeed may be insufficient.

Incidentally, my patient requiring all the work has failed his half hour appointment. I can't charge him for this, or claim any UDAs, making his treatment even more costly for me.

Is it me, or is someone trying to destroy NHS dentistry once and for all?

\section{H. Walker}

\section{Barnsley}

doi: $10.1038 /$ sj.bdj.4813729

\section{Commitment to accessibility}

Sir, I write in response to J. Ludford's letter (BDJ 2006; 200: 473).

The General Dental Council is committed to being open, accessible and accountable for its actions. Members of the public and dental professionals need access to information about our work so they may have confidence that we are fulfilling our public protection role.

Conduct hearings are public inquiries into the fitness to practise of dental professionals. Patients, other dental professionals, employers and others, all have a legitimate interest in the outcome of these hearings. That is why we consider it important to publish the details of cases in our newsletter (the Gazette) and on our website. Contrary to the writer's claim, no one is stripped of their 'courtesy title' in these reports. The GDC itself does not generally use the courtesy title 'Doctor' when writing to or about dentists.

The fee dentists pay for registration represents the true cost of regulation. The GDC is a non profit making organisation. The General Medical Council does charge doctors a lower fee, but with more than 230,000 registrants (the GDC has fewer than 40,000), this is a reflection of substantial economies of scale.

We do not offer free registration or reduced fees to dentists over the age of 65 as it would increase the charge to other registrants - very many of whom work part-time or have relatively modest earnings, for example, those studying medicine.

The GMC has obtained the necessary legal changes to have a non-practising list, for which those registrants will pay a lower fee. Currently, the law does not permit the GDC a 'non-practising' category. However, this is something we will be exploring as part of our work towards the introduction of a revalidation scheme for dental professionals.

\section{H. Mathewson}

GDC President

doi: 10.1038/sj.bdj.4813730 